\title{
LA SITUACIÓN JURÍDICA DE LA GESTACIÓN POR SUSTITUCIÓN EN ESPAÑA
}

\author{
Jagdish Kumar Chulani Raymond* \\ Profesor asociado de Derecho Civil \\ Universidad de La Laguna
}

\section{Resumen}

El presente trabajo trata de realizar una aproximación inicial al fenómeno de la gestación subrogada en nuestro país. El artículo 10 de la Ley 14/2006, de 26 de mayo, sobre Técnicas de Reproducción Humana Asistida dispone de forma expresa que (a) Será nulo de pleno derecho el contrato de gestación subrogada; (b) La filiación de los hijos nacidos por gestación de sustitución será determinada por el parto. Sin embargo, y pese a la claridad del precepto, actualmente se puede inscribir en nuestro Registro Civil a los hijos de españoles nacidos en el extranjero mediante esta técnica de reproducción, siempre que se cumpla con los requisitos formales que se establecen en la Instrucción de 5 de octubre de 2010, de la Dirección General de los Registros y del Notariado, sobre régimen registral de la filiación de los nacidos mediante gestación por subrogación.

Palabras clave: gestación subrogada, padres comitentes, filiación, orden público internacional, interés superior del menor.

\author{
THE LEGAL SITUATION OF GESTATION \\ BY SUBSTITUTION IN SPAIN
}

\section{Abstract}

This paper attempts to make an initial assessment of the phenomenon of surrogate pregnancy in our country. Article 10 of the Spanish Law 14/2006 of 26th May on Assisted Human Reproduction Techniques expressly provides that: (a) The surrogate gestation contract shall be null and void; (b) The filiation of children born by substitute pregnancy shall be determined by childbirth. However, despite the clarity of the precept, Spanish children born abroad can now be registered in the Civil Registry by means of this reproduction technique, provided that the formal requirements laid down in the Instruction of 5th October 2010 of the Directorate-General for Registers and Notaries on filiation registration of children born through surrogate pregnancy are met.

KEYWORDS: surrogate pregnancy, intended parents, filiation, international public policy, interests of the child. 


\section{PLANTEAMIENTO}

La moralidad de una generación cambia con respecto a otra debido a que la sociedad se encuentra en continua transformación. Así, los avances de la ciencia médica han contribuido a que no sólo el modelo de familia tradicional ${ }^{1}$ se transforme, sino también las formas de concebir a los descendientes. De este modo, surge la gestación por sustitución ${ }^{2}$, con sus distintas modalidades, como la subrogación tradicional (traditional surrogacy) o total, en donde la mujer gestante es inseminada artificialmente, aportando su propio óvulo, y en consecuencia heredando el nasciturus su información genética; y la subrogación gestacional (gestational surrogacy) o parcial, en donde la embarazada no tiene ningún vínculo ${ }^{3}$ genético con el concebido, pues es la cedente del óvulo la que transmite sus genes ${ }^{4}$.

Desde un punto de vista religioso, confesiones como judaísmo ${ }^{5}$ o el islam no prohíben la maternidad subrogada. De hecho, en los países de credo musulmán un hombre puede contraer nupcias con una segunda mujer ${ }^{6}$, y ésta someterse luego a un proceso de inseminación con el óvulo de la primera esposa ${ }^{7}$.

En el plano jurídico internacional distinguimos tres opciones:

* Profesor asociado del Departamento de Disciplinas Jurídicas Básicas de la Universidad de La Laguna, jchulani@ull.edu.es.

${ }_{1}$ El Código civil español en su redacción originaria de 1989, siguiendo los criterios del Code civil napoleónico de 1804, adoptó el sistema de la concepción formalista, adaptándose así al modelo social imperante en la época, basado en la llamada familia tradicional. Díaz Fraile, J.M., «La gestación por sustitución ante el Registro Civil espańol. Evolución de la doctrina de la DGRN y de la jurisprudencia española y europea», Revista de Derecho Civil, vol. vi, núm. 1 (enero-marzo), 2019, p. 59.

2 La llamada gestación por sustitución consiste en un contrato, oneroso o gratuito, a través del cual una mujer consiente en llevar a cabo la gestación, mediante técnicas de reproducción asistida, aportando o no también su óvulo, con el compromiso de entregar el nacido a los padres comitentes (intended parents), que pueden ser una persona o una pareja, casada entre sí o no, que a su vez pueden aportar o no sus gametos. Vid. F.J. 1. ${ }^{\circ}$ de la Sentencia de la Audiencia Provincial de Valencia, número 949/2011, de 23 de noviembre de 2011.

${ }^{3}$ Nótese que incluso en estos casos existe relación entre la mujer gestante y el bebé (vínculo gestacional). Véase el Informe sobre aspectos éticos y jurídicos de la maternidad subrogada, elaborado por el Comité de Bioética de España en 2017, pp. 12-16. Disponible en https://eprints.ucm. es/id/eprint/42816/ (último acceso: 10/1/2021).

${ }^{4}$ Ver mi artículo periodístico «Ser padres a través de una madre de alquiler», Revista Canaria de la Salud, núm. 24 (abril), 2014, pp. 90-91.

5 El judaísmo apoya la gestación por sustitución con ciertas condiciones, como por ejemplo que la mujer gestante sea de religión judía.

${ }^{6}$ Sura IV, aleya 3, Libro Sagrado Corán: «Si teméis no ser equitativos con los huérfanos, entonces, casaos con las mujeres que os gusten: dos, tres o cuatro. Pero si teméis no obrar con justicia, entonces con una sola».

7 No obstante, el hecho de que un hombre musulmán se case con una segunda esposa y tenga un hijo con ella mediante esta técnica de reproducción humana asistida no impide que luego se pueda divorciar de ella. 
- Países que la prohíben, como por ejemplo Francia o el nuestro, en donde el contrato de gestación por subrogación es nulo de pleno derecho.

- Estados que la permiten, siempre que no medie precio y se realice de forma altruista, como por ejemplo Bélgica ${ }^{8}$.

- Y otros que la promocionan, como por ejemplo algunos estados de EE. UU.?

En el presente artículo hemos querido abordar el estudio de la maternidad subrogada desde la perspectiva española. Una cuestión polémica no sólo en nuestro ámbito jurídico interno, sino también en el marco internacional ${ }^{10}$. Un fenómeno propio de la época en la que nos ha tocado vivir, sin precedentes en la historia, fruto del avance de la ciencia ${ }^{11}$, y que en cualquier caso puede suponer la quiebra del principio formulado por el jurista romano Paulo mater semper certa est ${ }^{12}$. Lo que nos lleva a plantearnos preguntas de difícil respuesta, tales como si son todas las formas de concepción válidas para nuestro sistema de valores occidenta ${ }^{13}$; o cuáles son los efectos de un contrato nulo cuyo objeto sea el alumbramiento de un hijo ${ }^{14}$. Todas estas controversias surgen cuando nos aproximamos a esta materia desde una perspectiva tanto moral como jurídica, cuya consideración permitirá al lector esgrimir argumentos a favor y en contra de este novedoso contrato, siendo complicado, a nuestro modo de ver, encontrar una solución colmada de virtudes a priori.

La posibilidad de que otra mujer distinta a la madre intencional geste un embrión ha sido una posibilidad con la que durante siglos ha soñado el ser humano. De hecho, podemos encontrar precedentes que guardan relación con este contrato

${ }^{8}$ Como consecuencia de una admisión indirecta a través de una situación de práctica tolerancia.

${ }^{9}$ De los cincuenta estados que conforman EE. UU., esta técnica se permite sólo en algunos, como por ejemplo California, Connecticut, Florida, Idaho, Illinois, Nevada o Utah.

${ }^{10}$ En la siguiente página web se puede consultar la situación de la gestación subrogada en distintos países de la comunidad internacional: https://babygest.com/es/tag/maternidad-subrogada/ (último acceso: 2/1/2021).

${ }^{11}$ Que, por ejemplo, permite que los matrimonios homosexuales de varones puedan superar la impotencia generandi a través de esta técnica de reproducción humana asistida.

${ }_{12}$ Digesto de Justiniano, tomo I, libro 2, título 4, apartado 5. La mayoría de las legislaciones reconoce la maternidad legal de la mujer que dio a luz al hijo alegando este antiguo axioma romano. A diferencia de la paternidad, que se funda en presunciones que parten de la existencia de matrimonio - pater est quem nuptiae demonstrant-y de los deberes de cohabitación y fidelidad de los cónyuges entre sí dentro del propio matrimonio, el vínculo de filiación respecto de la madre resulta siempre de dos hechos susceptibles de prueba directa. El primero es el parto de la madre y el segundo la identidad del descendiente, esto es, la determinación de que el hijo o la hija es realmente el que la mujer dio a luz. Vela Sánchez, A.J., La maternidad subrogada: estudio ante un reto normativo, Comares, Granada, 2012, p. 31.

${ }_{13}$ Desde luego este tipo de gestación nos lleva a replantearnos el concepto jurídico y ético de la maternidad. En este sentido ver Quicios Molina, S., "Regulación por el ordenamiento espanól de la gestación por sustitución: dónde estamos y hasta dónde podemos llegar», Revista de Derecho Privado, núm. 1, enero-febrero, Reus, 2019, pp. 6-8.

${ }_{14}$ ¿No estamos ante una res extra commercium? 
en pasajes bíblicos ${ }^{15}$. Pero no nos vamos a centrar en estas páginas en cuestiones relacionadas con fuentes historiográficas, o en regulaciones de otros ordenamientos jurídicos, al no ser éste un estudio de derecho comparado.

Lo que pretendemos es realizar un somero análisis de la situación jurídica actual en España de los menores nacidos mediante gestación por sustitución, pues muchos son los ríos de tinta que han corrido sobre este controvertido tema, no sólo en los distintos medios de comunicación, sino también en la literatura especializada en derecho privado ${ }^{16}$. Para ello, hemos hecho una recopilación de las distintas fuentes normativas relacionadas con este fenómeno; las resoluciones e instrucciones de la Dirección General de los Registros y del Notariado (en adelante, DGRN ${ }^{17}$ ); las sentencias de nuestros tribunales de justicia, todo ello complementado por los imprescindibles comentarios de la doctrina científica; hasta los intentos por regular mediante ley esta nueva forma de concepción de la descendencia ${ }^{18}$.

Con el objetivo de poder realizar un estudio coherente, todas las fuentes utilizadas se irán citando por orden cronológico. El lector podrá así observar la evolución jurídica en España de la situación de estos menores, que en muchas ocasiones parecen encontrarse en una especie de limbo jurídico.

Aunque estamos ante un estudio de derecho civil, no podemos ignorar el necesario elemento de extranjería que está presente en estos negocios jurídicos, pues sin la cobertura de otros ordenamientos jurídicos sería imposible conseguir el resultado perseguido por las partes contratantes, ya que incluso podría ser constitutivo de sanción penal, tal y como prevén los artículos 220 a 222 del Código Penal (RCL $1995(3170)^{19}$.

15 Génesis: 16:1 Sarai mujer de Abram no le daba hijos; y ella tenía una sierva egipcia, que se llamaba Agar. 16:2 Dijo entonces Sarai a Abram: Ya ves que Jehová me ha hecho estéril; te ruego, pues, que te llegues a mi sierva; quizá tendré hijos de ella. Y atendió Abram al ruego de Sarai. 16:3 Y Sarai mujer de Abram tomó a Agar su sierva egipcia, al cabo de diez años que había habitado Abram en la tierra de Canaán, y la dio por mujer a Abram su marido. 16:4 Y él se llegó a Agar, la cual concibió; y cuando vio que había concebido, miraba con desprecio a su señora. Génesis: 30:1 Viendo Raquel que no daba hijos a Jacob, tuvo envidia de su hermana, y decía a Jacob: Dame hijos, o si no, me muero. 30:2 Y Jacob se enojó contra Raquel, y dijo: ¿Soy yo acaso Dios, que te impidió el fruto de tu vientre? 30:3 Y ella dijo: He aquí mi sierva Bilha; llégate a ella, y dará a luz sobre mis rodillas, y yo también tendré hijos de ella. 30:4 Así le dio a Bilha su sierva por mujer; y Jacob se llegó a ella. 30:5 Y concibió Bilha, y dio a luz un hijo a Jacob.

16 Sobre todo, civilista e internacional-privatista.

17 El Real Decreto 139/2020, de 28 de enero, por el que se establece la estructura orgánica básica de los departamentos ministeriales, ha cambiado la denominación de la DGRN por Dirección General de Seguridad Jurídica y Fe Pública. No obstante, en este estudio continuaremos refiriéndonos a ella como DGRN.

${ }_{18}$ Pese al considerable descenso de la tasa de natalidad en nuestro país. En la página web del Instituto Nacional de Estadística se puede consultar la tasa de natalidad por comunidades autónomas, según nacionalidad (española/extranjera) de la madre. Disponible en https://www.ine.es/ jaxiT3/Tabla.htm?t=1433 (último acceso: 4/01/2021).

${ }^{19}$ Delitos relativos a la suposición de parto y de la alteración de la paternidad, estado o condición del menor. A fecha de realización del presente trabajo no se han encontrado sentencias condenatorias relacionadas con las conductas típicas, antijurídicas, culpables y punibles mencionadas. 
Por último, sólo esperamos que el lector se sumerja a través de este sucinto artículo, en el que, sin duda, será uno de los grandes hitos de la humanidad para unos, y la cosificación de la mujer para otros. Como todo en la vida, la gestación por subrogación tiene sus luces y sus sombras.

\section{LA GESTACIÓN POR SUBROGACIÓN: MODALIDADES Y REFERENCIA A LAS TÉCNICAS DE REPRODUCCIÓN HUMANA ASISTIDA}

Sin entrar a profundizar en su delimitación conceptual, la gestación subrogada consiste en el supuesto por el que una pareja comitente, o una persona sola, realiza un contrato ${ }^{20}$ con una madre subrogada (también denominada sustituta, portadora o de alquiler) con el objetivo de que, previa inseminación o transferencia de un embrión fecundado in vitro, dé a luz al niño deseado, siendo éste considerado como hijo de la pareja o persona comitente.

Pese a la rotunda prohibición contenida en el artículo $10.1^{21}$ de la Ley 14/2006, de 26 de mayo, de Técnicas de Reproducción Humana Asistida (RCL 2006\1071, en lo sucesivo LTRHA), que establece la nulidad del contrato de gestación ${ }^{22}$, en la práctica nos encontramos con una abundante casuística de familias tanto heteroparentales como homoparentales o incluso monoparentales ${ }^{23}$ que están

${ }^{20}$ En el que podría afirmarse que la obligación básica que asume la madre gestante es una obligación de resultado. SÁNCHEz JoRdán, M.E., «La necesaria doble aproximación a la gestación subrogada. En particular, de los olvidados contratos de gestación por sustitución», InDret Privado, Revista para el Análisis del Derecho, n. ${ }^{\circ}$ 4, 2020, p. 124.

${ }_{21}$ Dispone el artículo 10.1 LTRHA que «Será nulo de pleno derecho el contrato por el que se convenga la gestación, con o sin precio, a cargo de una mujer que renuncia a la filiación materna a favor del contratante o de un tercero". Destaca que el contenido de este artículo sea exactamente igual al de su correlativo en la ya derogada Ley 35/1988, de 22 de noviembre, sobre Técnicas de Reproducción Asistida (RCL 1988\2332). La última modificación de esta Ley fue la introducida por la Ley 19/2015, de 13 de julio, de medidas de reforma administrativa en el ámbito de la Administración de Justicia y del Registro Civil (RCL 2015\1082). Esta prohibición de la gestación por sustitución en nuestro ordenamiento jurídico tiene su origen en el informe de la Comisión especial de la fecundación in vitro y la inseminación artificial humanas, bajo la Presidencia de D. Marcelo Palacios Alonso, aprobado por el Congreso de los Diputados el 10 de abril de 1986.

22 Podríamos decir que el contrato es nulo no sólo por lo dispuesto en el artículo 10 LTRHA, sino en base a otros artículos del Código Civil (LEG 1889\27), como el 1255, el 1271 o el 1275.

${ }^{23}$ Como por ejemplo el matrimonio estadounidense formado por el actor Matthew John Broderick y la actriz Sarah Jessica Parker; el matrimonio formado por el cantante británico Elton John y el cineasta canadiense David Furnish; el futbolista portugués Cristiano Ronaldo o la coleccionista de arte Carmen Cervera, nacida en España, y viuda del barón alemán Hans Heinrich von Thyssen-Bornemisza. Vid. la noticia en el periódico El Pais, 20-06-2018, disponible en https://smoda. elpais.com/celebrities/estos-famosos-han-recurrido-a-los-vientres-de-alquiler-para-ser-padres/ (último acceso: 5-01-2021). 
acudiendo a países en los que tal contrato ${ }^{24}$ no está prohibido, con el fin de obtener descendencia. Se trata de una vía ${ }^{25}$ para burlar la prohibición legal del artículo 10.1 LTRHA.

Estas técnicas de reproducción engloban un conjunto de procedimientos que implican la intervención médica en al menos alguna de las fases de la procreación $^{26}$, las cuales podemos clasificar de la siguiente forma:

- Inseminación artificial. Consiste en la introducción del esperma en la vagina o útero de una mujer por cualquier medio distinto de la relación sexual. Puede ser homóloga ${ }^{27}$ o heteróloga ${ }^{28}$. Gregorio MARAÑón afirma en su obra Ensayo biológico sobre Enrique IV de Castilla y su tiempo que fue en España y en la persona de la reina, Dña. Juana de Portugal, a quien primero se le aplicó una inseminación artificial homóloga ${ }^{29}$.

- Fecundación in vitro. En este supuesto la fecundación del óvulo se realiza en un laboratorio, ante la imposibilidad de que el semen se fertilice en el tercio externo de las trompas de Falopio. Puede ser también homóloga ${ }^{30}$ o heteró$\operatorname{loga}^{31}$. La primera niña que nació como consecuencia de este tipo de fecundación fue Louise Brown, en el año 1978, en Londres ${ }^{32}$.

- Transferencia intratubárica de gametos. Consiste en colocar en cada una de las trompas de Falopio dos óvulos y espermatozoides para que los fecunden en las mismas trompas.

- Gestación por sustitución. Como hemos dicho con anterioridad, esta técnica consiste en que una mujer lleva en su cuerpo implantado un embrión hasta el

${ }^{24}$ Cuyas posibles partes intervinientes son los comitentes, la agencia intermediaria (como por ejemplo Surrobaby, Gestlife o la Agencia Española de Gestación Subrogada [AEGES]), la mujer gestante y los donantes del material genético. No obstante, en los últimos años ha entrado en escena un nuevo elemento, que permite alterar la aproximación habitual a ese fenómeno y centrar la atención en el análisis del contrato en virtud del cual se acuerda encargar a una mujer la gestación de un bebé a cuya filiación renuncia por anticipado. SANCHEZ Jordán, M.E., op. cit., p. 120. Ver también la Sentencia de la Audiencia Provincial de Barcelona, número 10/2019, del 15 de enero de 2019 (JUR 2019\25547); y la Sentencia de la Audiencia Provincial de Zaragoza número 38/2019, de 15 de febrero de 2019 (JUR 2019\185867).

${ }^{25}$ Que ha derivado en lo que ha llegado a denominarse «turismo reproductivo, procreativo o de fertilidad».

${ }^{26}$ Leonsegui Guillot, R.A., "La maternidad portadora, sustituta, subrogada o de encargo", Boletín de la Facultad de Derecho de la UNED, segunda época, número 7, invierno 1994, p. 318 .

27 En aquellos casos en los que la mujer es inseminada con el semen del marido.

${ }^{28}$ En aquellos supuestos en los que la mujer es inseminada con el semen de un tercero ajeno a la relación.

29 Díaz-Ambrona Bardají, M.D., Ponencia "Genética y filiación», XIII Congreso Internacional de Derecho de Familia, Sevilla, 2004, p. 10.

${ }^{30}$ Los gametos provienen de los cónyuges o parejas convivientes.

${ }^{31}$ Los gametos han sido donados por terceras personas previamente.

32 Díaz-Ambrona Bardají, M.D, op. cit., p. 11. 
nacimiento, para el beneficio de otra pareja o persona. No obstante, podemos distinguir las siguientes cuatro modalidades de gestación por sustitución ${ }^{33}$ :

1) Aportación por la pareja comitente únicamente del semen de un varón, mientras que la mujer sustituta aporta su óvulo y llevará acabo la gestación. Se trata de la denominada maternidad subrogada tradicional (traditional surrogacy), plena o total, realizada normalmente a través de inseminación artificial. De esta manera, la mujer sustituta será madre biológica del nacido, además de ser quien le dará a luz, y un varón de la pareja comitente su padre biológico ${ }^{34}$.

2) Aportación por la pareja comitente de la totalidad del material genético, de modo que la mujer sustituta únicamente llevará acabo la gestación. Por tanto, los progenitores biológicos del nacido serán los miembros de la pareja comitente ${ }^{35}$.

3) Aportación por la pareja comitente solamente de los gametos de uno de ellos (sólo el semen o sólo el óvulo), que se combinarán con los gametos de una cuarta persona, que será el donante de ovocitos o semen respectivamente. Nuevamente, la mujer sustituta únicamente llevará a cabo la gestación, sin aportar material genético alguno, siendo padres biológicos el miembro de la pareja comitente que aportó sus gametos y el donante ${ }^{36}$.

4) No aportación de gametos por la pareja comitente, obteniéndolos de donantes de semen y ovocitos. Al igual que en la situación anterior, la mujer sustituta únicamente llevará a cabo la gestación, sin aportar material genético alguno, pero ahora serán padres biológicos del nacido los correspondientes donantes ${ }^{37}$.

Estos tres últimos supuestos serían variantes de la denominada maternidad subrogada gestacional (gestational surrogacy) o parcial, caracterizada por el hecho de que la gestante no aporta material genético propio, disociándose la maternidad genética y la gestación ${ }^{38}$. De hecho, el caso más sencillo se produce cuando los titulares de las células germinales coindicen totalmente con los miembros de la pareja comitente, quienes aportan tanto el semen como el óvulo, produciéndose así una

${ }^{3}$ Jiménez MuÑoz, F.J., La reproducción asistida y su régimen jurídico, Reus, Colección Jurídica General, Madrid, 2012, p. 105.

34 Jiménez Muñoz, F.J., op. cit., p. 106.

35 Jiménez Muñoz, F.J., op. cit., p. 107.

36 Jiménez Muñoz, F.J., op. cit., p. 107.

37 Jiménez Muñoz, F.J., op. cit., p. 107.

38 Jiménez Muñoz, F.J., op. cit., p. 107. La posibilidad que ofrecen las técnicas de reproducción de disociar la maternidad en tres elementos (genético, gestacional y volitivo), que pueden no coincidir en la misma mujer, ha aportado complejidad a una cuestión en principio pacífica y ha planteado nuevos retos al legislador. FArnós Amorós, E., $A D C$, tomo LXVIII, fascículo I, 2015, p. 9. 
fecundación in vitro homóloga para luego implantar el cigoto en el útero de la mujer que llevará acabo el embarazo. Todas estas combinaciones dan lugar al fenómeno de la maternidad subrogada, que irremediablemente producirá una contraposición de intereses entre la pareja comitente, que aportó el huevo fecundado, y la portadora, que es la madre, en cuanto que gesta y alumbra al nacido ${ }^{39}$.

Por último, aparece unánimemente descartado del fenómeno de la maternidad subrogada la utilización animal, como los rumores de querer convertir a una simia en portadora de un embrión humano ${ }^{40}$.

\section{POSTURA DE LA DIRECCIÓN GENERAL DE LOS REGISTROS Y DEL NOTARIADO SOBRE LA GESTACIÓN SUBROGADA}

Pese a la prohibición contenida en el artículo 10.1 LTRHA, numerosos ciudadanos españoles han salido de nuestras fronteras en busca de países que admitan los contratos de gestación por sustitución con la intención de poder acceder a la paternidad. Ante esta situación, la DGRN trató de dar una solución administrativa, en contra de lo dispuesto en la referida LTRHA, fundamentada en el Reglamento del Registro Civil aprobado por el Decreto de 14 de noviembre de 1958 (RCL 1958\1957, en adelante $\mathrm{RRC}$ ), $y$, por tanto, en detrimento del principio de jerarquía normativa.

\subsection{Resolución de la Dirección General de los Registros y del Notariado, DE 18 DE FEBRERO DE 2009}

La primera vez que este centro directivo tuvo que pronunciarse sobre esta materia fue con la Resolución de la Dirección General de los Registros y del Notariado, de 18 de febrero de 2009 (RJ 2009\1735, en adelante RDGRN), por la que se admitió la pretensión de un matrimonio, formado por dos varones ${ }^{41}$, de nacionalidad española y residentes en España, de inscribir a dos menores, nacidos en San

39 Leonsegui Guillot, R.A.: op. cit., p. 323.

40 Higuera, G., «Biogenética y Derecho», Revista Española de Derecho Canónico, 44, Madrid, 1987, p. 13.

${ }_{41}$ Casados en octubre de 2005, pocos meses después de la entrada en vigor de la Ley 13/2005, de 1 de julio, por la que se modifica el Código Civil en materia de derecho a contraer matrimonio (RCL 2005\1407). Ver también Sentencia del Tribunal Constitucional, número 198/2012, de 6 noviembre de 2012 (RTC 2012\198), por la que se desestima el recurso de inconstitucionalidad interpuesto por el Grupo Popular del Congreso contra la citada Ley 13/2005, de 1 de julio. 
Diego el 24 de octubre de 2008, como hijos ${ }^{42}$ suyos, aportando los certificados de nacimiento ${ }^{43}$, expedidos por las autoridades californianas ${ }^{44}$.

Dicha RDGRN trae causa de la denegación por parte del canciller encargado del Registro Civil Consular de España en Los Ángeles-California (EE. UU.), en su Auto de 10 de noviembre de 2008, de la inscripción solicitada por parte del referido matrimonio homosexual, con base en el artículo 10 LTRHA y en la prohibición de la celebración, en nuestro ordenamiento jurídico, del contrato de gestación subrogada. Este auto se recurrió por parte del matrimonio ante DGRN, quien estimó la pretensión de los recurrentes en su RDGRN, y en consecuencia autorizó la inscripción en el Registro Civil del nacimiento de los menores y su respectiva filiación a favor del matrimonio ${ }^{45}$.

Los principales fundamentos de derecho en los que se sustenta la RDGRN son los siguientes:

En primer lugar, el artículo 81 del RRC establece que «El documento auténtico, sea original o testimonio, sea judicial, administrativo o notarial, es título para inscribir el hecho de que da fe. También lo es el documento auténtico extranjero, con fuerza en España con arreglo a las leyes o a los Tratados internacionales». En virtud de ello, entiende la DGRN que la misión del encargado del Registro Civil se tiene que limitar a realizar un control formal de legalidad de la decisión registral extranjera. La aplicación del artículo $81 \mathrm{RRC}$ excluye, por tanto, la utilización de las normas españolas de conflicto de leyes y, en concreto, la del artículo 9.4 CC. Por tanto, también excluye la aplicación de la Ley sustantiva a la que tales normas de conflicto españolas pudieran conducir, como la LTRHA. Las normas de conflicto españolas y las normas sustantivas designadas por tales normas de conflicto son sólo aplicables a los supuestos que surgen ante las autoridades españolas sin que haya sido dictada una decisión por la autoridad pública extranjera. Por consiguiente, son aplicables en el presente caso las normas jurídicas españolas que regulan el acceso al Registro Civil español de las certificaciones regístrales extranjeras, esto es, el artículo 81 RRC y no las normas de conflicto españolas y tampoco las normas sustantivas españolas que determinan la filiación ${ }^{46}$.

${ }^{42}$ Biológicos de ambos, ya que lo que pretendían era obtener la doble filiación paterna, evitando así, los padres de intención, el tener que recurrir a otras instituciones como la adopción o el acogimiento familiar.

${ }^{43}$ En los que se constataba la paternidad a favor de los recurrentes de dos niños mellizos nacidos de una madre subrogada en California a partir de material genético de uno de los recurrentes y de óvulos de donante anónima. Heredia Cervantes, I., «La Dirección General de los Registros y del Notariado ante la gestación por sustitución», $A D C$, tomo LXVI, fascículo II, 2013, p. 695.

${ }^{44}$ Estas certificaciones registrales extranjeras fueron emitidas por la autoridad administrativa del Registro de California (The California Office of Vital Records).

${ }^{45}$ Jiménez Martínez, M.V., «La inscripción de la filiación derivada de la gestación por sustitución. Problemas actuales», Anuario de la Facultad de Derecho de la Universidad de Alcalá, núm. 5, 2012, p. 371.

46 Vid. F.D.2. de la RDGRN de 18 de febrero de 2009. 
En segundo lugar, el interés superior del menor aconseja proceder a la inscripción en el Registro Civil español de la filiación que figura en el Registro extranjero y en la certificación registral extranjera, ya que, en el caso de rechazar la inscripción de la filiación en el Registro Civil español, podría resultar que los hijos, de nacionalidad española, quedarían privados de una filiación inscrita en el Registro Civil. Ello vulnera el artículo 3 de la Convención sobre los Derechos del Niño hecha en Nueva York el 20 noviembre 1989 (BOE número 313 de 31 diciembre 1990 [RCL 1990\2712]), en vigor para España desde el 5 de enero de $1991^{47}$.

Y, en tercer lugar, en el derecho español, la filiación natural no se determina necesariamente por el hecho de la vinculación genética entre los sujetos implicados, como se deduce del artículo 7.3 LTRHA ${ }^{48}$, precepto que permite que la filiación natural de un hijo conste en el Registro Civil a favor de dos mujeres. Por ello, no existen obstáculos jurídicos a la inscripción en el Registro Civil español de una certificación registral extranjera que establezca la filiación en favor de dos varones españoles ${ }^{49}$.

Sin embargo, esta RDGRN fue recurrida en sede judicial por el Ministerio Fiscal, el 28 de enero de 2010, al presentarse en el Decanato de los Juzgados de Valencia demanda contra la RDGRN, que recayó en el Juzgado de Primera Instancia número 15, cuyo titular, mediante Sentencia de 15 de septiembre de 2010 (AC 2010\1707), estimó íntegramente la demanda interpuesta por el Ministerio Fiscal contra la RDGRN, dejando sin efecto la inscripción de nacimiento de los menores, realizada en el Registro Civil Consular de Los Ángeles, y, en consecuencia, procediéndose a la cancelación del asiento de inscripción.

\subsection{InSTRUCCIÓN DE 5 DE OCTUbRe De 2010, SObRe RÉGIMEN REGISTRAL DE LA FILIACIÓN DE LOS NACIDOS MEDIANTE GESTACIÓN POR SUSTITUCIÓN}

En el año 2010, la DGRN dio un paso más en la regulación de las condiciones de acceso al Registro Civil de los niños nacidos en el extranjero de madres gestantes que, en virtud del recurso a un contrato de gestación subrogada, han renunciado con carácter anticipado a su filiación materna. Para ello, el centro directivo dictó la Instrucción de 5 de octubre de 2010, sobre régimen registral de la filiación de los nacidos mediante gestación por sustitución (RLC 2010〈2624), que establece

$47 \mathrm{Vid}$. F.D.5. ${ }^{\circ}$ de la RDGRN de 18 de febrero de 2009.

48 Cuando la mujer estuviere casada, y no separada legalmente o de hecho, con otra mujer, esta última podrá manifestar, conforme con lo dispuesto en la Ley del Registro Civil, que consiente en que se determine a su favor la filiación respecto al hijo nacido de su cónyuge (artículo incorporado por la Ley 3/2007, de 15 de marzo, reguladora de la rectificación registral de la mención relativa al sexo de las personas [RCL 2007\524]). No obstante, este artículo establece la imposición legal de contraer matrimonio a las parejas de mujeres, antes del alumbramiento del hijo, siendo ésta hasta ahora la única forma de poder determinar la filiación del menor a favor de la madre no gestante, a menos que, una vez nacido el menor, inicie los trámites de adopción.

${ }^{49}$ Vid. F.D.5. ${ }^{\circ}$ cit. de la RDGRN. 
unos criterios para el acceso al Registro Civil español de los menores nacidos en el extranjero mediante esta técnica de reproducción humana asistida. No obstante, el objetivo esencial ${ }^{50}$ de la Instrucción, contemplado desde una perspectiva global, fue establecer:

1. ${ }^{\circ}$ Los instrumentos necesarios para que la filiación tenga acceso al Registro Civil español cuando uno de los progenitores sea de nacionalidad española, como vía de reconocimiento a efectos registrales de su nacimiento.

2. ${ }^{\circ}$ Que la inscripción registral en ningún caso puede permitir que con la misma se dote de apariencia de legalidad supuestos de tráfico internacional de menores.

3. ${ }^{\circ}$ La exigencia de que no se haya vulnerado el derecho del menor a conocer su origen biológico ${ }^{51}$.

Sin embargo, lo más novedoso de la Instrucción fue que, en ejercicio de las competencias que le vienen atribuidas por el artículo 9 de la Ley del Registro Civil, de 8 de junio 1957 (RCL 1957\777, en adelante, LRC), 41 RRC y 7 del Real Decreto $1125 / 2008$, de 4 de julio, por el que se desarrolla la estructura orgánica básica del Ministerio de Justicia y se modifica el Real Decreto 438/2008, de 14 de abril, por el que se aprueba la estructura orgánica básica de los departamentos ministeriales, acordó establecer y hacer públicas las siguientes directrices:

1. La inscripción de nacimiento de un menor, nacido en el extranjero como consecuencia de técnicas de gestación por sustitución, sólo podrá realizarse presentando, junto a la solicitud de inscripción, la resolución judicial dictada por el tribunal competente en la que se determine la filiación del nacido ${ }^{52}$.

2. Salvo que resultase aplicable un convenio internacional, la resolución judicial extranjera deberá ser objeto de exequatur según el procedimiento contemplado en la Ley de Enjuiciamiento Civil de 1881 (LEG 1881\1) ${ }^{53}$. Para prolimbo jurídico.

50 Además de evitar que la determinación de la filiación de estos menores quedase en un

${ }^{51}$ Según se expresa en el artículo 7, número 1, de la Convención sobre los Derechos del Nińo de 20 de noviembre de 1989, en el artículo 12 de la Ley 54/2007, de 28 de diciembre, de Adopción Internacional (RCL 2007\2383), así como en la Sentencia del Tribunal Supremo de 21 de septiembre de 1999 (RJ 1999\6944).

52 En los casos en los que se solicite la inscripción del nacido en el extranjero mediante gestación por sustitución sin que se presente una resolución que determine la filiación, reconocible incidentalmente o por exequatur, el encargado del Registro Civil denegará la inscripción. Ello no impedirá que el solicitante pueda intentar dicha inscripción por los medios ordinarios regulados en el artículo 10.3 LTRHA y en los artículos 764 y siguientes de la Ley 1/2000, de 7 de enero, de Enjuiciamiento Civil (RCL 2000\34).

53 En los artículos 951 a 958 ya derogados por el número 1 de la disposición derogatoria única de la Ley 29/2015, de 30 de junio, de cooperación jurídica internacional en materia civil (RCL 2015\1200, en adelante, LCJIMC), y ahora regulado por los artículos 52 a 55 de la LCJIMC. No obstante, es causa de denegación del reconocimiento de resoluciones judiciales extranjeras firmes el ser contraria al orden público, conforme con lo dispuesto en el artículo 46.1 a) LCJIMC. Sin 
ceder a la inscripción de nacimiento, deberá presentarse ante el Registro Civil español la solicitud de la inscripción y el auto judicial que ponga fin al mencionado procedimiento de exequatur.

3. No obstante, en el caso de que la resolución judicial extranjera tuviera su origen en un procedimiento análogo a uno español de jurisdicción voluntaria, el encargado del Registro Civil controlará incidentalmente, como requisito previo a su inscripción, si tal resolución judicial puede ser reconocida en España. En dicho control incidental deberá constatar:

a. La regularidad y autenticidad formal de la resolución judicial extranjera y de cualesquiera otros documentos que se hubieran presentado.

b. Que el tribunal de origen hubiera basado su competencia judicial internacional en criterios equivalentes a los contemplados en la legislación española.

c. Que se hubiesen garantizado los derechos procesales de las partes, en particular, de la madre gestante.

d. Que no se ha producido una vulneración del interés superior del menor y de los derechos de la madre gestante. En especial, deberá verificar que el consentimiento de esta última se ha obtenido de forma libre y voluntaria, sin incurrir en error, dolo o violencia y que tiene capacidad natural suficiente.

e. Que la resolución judicial es firme y que los consentimientos prestados son irrevocables, o bien, si estuvieran sujetos a un plazo de revocabilidad conforme a la legislación extranjera aplicable, que éste hubiera transcurrido, sin que quien tenga reconocida facultad de revocación la hubiera ejercitado.

Además de todo lo anterior, dispone también la Instrucción que en ningún caso se admitirá como título apto para la inscripción del nacimiento y filiación del nacido una certificación registral extranjera o la simple declaración, acompañada de certificación médica relativa al nacimiento del menor en la que no conste la identidad de la madre gestante.

Hasta este momento, con la solución ofrecida por la Instrucción de la DGRN, el conflicto había obtenido una pseudorrespuesta, en tanto en cuanto no se produzca la derogación del artículo 10 LTRHA.

embargo, entre los presupuestos a los que se refiere la Instrucción de la DGRN no se encuentra la conformidad con el orden público español internacional, requisito que sí se exige en el artículo 96.2 d) de la Ley 20/2011, de 21 de julio, del Registro Civil (RCL 2011\1432, en lo sucesivo, LRC 2011, cuya entrada en vigor está prevista para el 30 de abril de 2021, conforme con lo dispuesto en la disposición final quinta de la Ley $3 / 2020$, de 18 de septiembre, de medidas procesales y organizativas para hacer frente al COVID-19 en el ámbito de la Administración de Justicia [RCL 202011497]) y en la disposición adicional tercera de la Ley 15/2015, de 2 de julio, de la Jurisdicción Voluntaria (RCL 2015\1016, en adelante, LJV). 
De esta forma se vuelve a dar validez en España a un evidente fraude de ley, ahora no sólo frente al claro tenor literal del artículo 10 LTRHA, sino frente a las sentencias que a continuación comentaremos, con el único apoyo jurídico de la Instrucción de la DGRN, cuyo valor normativo es ciertamente endeble ${ }^{54}$. Sin embargo, como veremos, el problema parece tener todavía un largo camino por recorrer.

\section{LA GESTACIÓN POR SUSTITUCIÓN ANTE LOS TRIBUNALES ESPAÑOLES}

Tal y como observaremos a continuación con la exposición del iter judicial de este fenómeno, tan analizado por la doctrina científica, la solución ofrecida por parte de los tribunales de justicia no ha sido la misma que la que ha establecido la DGRN.

\subsection{Sentencia del Juzgado de Primera Instancia número 15 de Valencia, DE 15 DE SEPTIEMBRE DE 2010}

La RDGRN, como hemos dicho anteriormente, fue recurrida por la Fiscalía y el Juzgado de Primera Instancia número 15 de Valencia dictó la Sentencia de 15 de septiembre de 2010, por la cual se revocó la citada RDGRN en aplicación del principio de jerarquía normativa reconocido en el artículo 9.3 de la Constitución (RCL 1978\2836), al considerar, el juzgador, preferente la aplicación del artículo 23 LRC, frente al artículo 81 RRC, ya que dicho Reglamento desarrolla y completa la ley citada.

Según reza el artículo 23 LRC: «Las inscripciones se practican en virtud de documento auténtico o, en los casos señalados en la Ley, por declaración en la forma que ella prescribe. También podrán practicarse, sin necesidad de previo expediente, por certificación de asientos extendidos en registros extranjeros, siempre que no haya duda de la realidad del hecho inscrito y de su legalidad conforme a la Ley española». Vemos por tanto que el mencionado artículo 23 LRC sí obliga al registrador a realizar un control de fondo del contenido de la certificación extranjera, puesto que se tiene que asegurar de que no incurra en contradicción con la Ley española, lo cual ocurría en este caso, al contradecir el contenido del artículo 10.1 LTRHA. Aparte, esta sentencia despejó cualquier duda respecto del principio de no discriminación. La DGRN consideró que, si se permite la inscripción de la filiación a favor de dos mujeres casadas, también se tendría que permitir la filiación a favor de dos varo-

${ }^{54}$ Martínez de Aguirre Aldaz, C., «Acciones de filiación. Filiación derivada de técnicas de reproducción asistida", en Martínez de Aguirre Aldaz, C. (coord.), Curso de Derecho Civil (IV) Derecho de Familia, Edisofer, 5. ${ }^{a}$ edición, Madrid, 2016, p. 375. 
nes casados ${ }^{55}$. A este respecto, considera el juzgador de instancia que la nulidad del contrato se deriva de las consecuencias que se producen tras el alumbramiento, con independencia del sexo de las personas, distintas de la madre gestante, que pretenden ostentar la filiación del nacido, por la existencia de un contrato de maternidad por sustitución ${ }^{56}$.

La Sentencia también determinó que el fin no justifica los medios, ya que el ordenamiento jurídico español tiene medios e instrumentos suficientes para conseguir esta concordancia y que los hijos consten a nombre de sus padres, pero la consecución de ese fin no legitima actuaciones contrarias a ese propio ordenamiento jurídico, sino que el resultado debe conseguirse a través de las vías que el derecho español establece ${ }^{57}$.

Algunos supuestos, con cierto parecido al tratado, son los referidos en el fundamento jurídico quinto de la Sentencia:

El primero de ellos es el acceso al Registro Civil de los matrimonios entre personas del mismo sexo contraídos en el extranjero con anterioridad a la Ley 13/2005, los cuales hasta la modificación del Código Civil tenían vedado el acceso al Registro Civil. Sin embargo, tras la entrada en vigor de la Ley 13/2005, se dictó la Resolución-Circular de 29 de julio de 2005 de la DGRN por la que se resuelve el reconocimiento en España de los matrimonios celebrados en el extranjero entre españoles, o entre españoles y extranjeros del mismo sexo, antes de la entrada en vigor de la citada Ley 13/2005, de 1 de julio. Tal vez sea éste el supuesto, de entre los que menciona el juzgador de primera instancia, que más similitudes presenta con respecto al fenómeno de la gestación subrogada, ya que, hasta la entrada en vigor de la Ley por la que se modifica el Código Civil en materia de derecho a contraer matrimonio, muchos espańoles recurrían a países en donde el contrato matrimonial entre personas del mismo sexo sí estaba regulado, con el objetivo de contraer nupcias.

El segundo supuesto que expone la Sentencia es el caso de matrimonios celebrados entre una menor y un español en el extranjero. Así, en países como Colombia, en donde la edad mínima exigida a una mujer para contraer matrimonio es de 12 años, el matrimonio allí celebrado entre una menor y un español no tendría acceso al Registro Civil español ${ }^{58}$.

El tercer caso al que hace referencia la Sentencia es el de los matrimonios poligámicos, legales en otros países, pero no inscribibles en el Registro Civil español. En nuestra opinión, consideramos que el tratar de relacionar los matrimonios polígamos con la maternidad por subrogación era del todo innecesario, más aún cuando en España, si bien es cierto que dichos matrimonios no son susceptibles de

55 Vid. F.D. 4. ${ }^{\circ}$ de la Sentencia del Juzgado de Primera Instancia número 15 de Valencia, de 15 de septiembre de 2010. De hecho, el artículo 7.3 LTRHA permite inscribir la filiación natural respecto de dos mujeres y sería discriminatorio por razón de sexo no permitirlo a dos varones.

56 Jiménez Martínez, M.V., op. cit., pp. 374-375.

57 Vid. F.D. $4 .^{\circ}$. cit. de la SJPI.

58 Conforme con lo dispuesto en el artículo 46 CC: «No pueden contraer matrimonio: $1 .^{\circ}$ Los menores de edad no emancipados». 
reconocimiento, el ordenamiento jurídico español sí que les ha venido atribuyendo efectos, como por ejemplo ocurre con el reparto de la pensión de viudedad entre las esposas legítimas del causante.

\subsection{Sentencia de la Sección Décima de la Audiencia Provincial de Valen- CIA, DE 23 DE NOVIEMBRE DE 2011}

Los padres comitentes, en su anhelo de conseguir el reconocimiento de la filiación de los menores y, por ende, de la prevalencia del principio de la autonomía de la voluntad de las partes, sobre la legalidad vigente del Estado español, interpusieron recurso de apelación frente a la Sentencia de 15 de septiembre de 2010, del Juzgado de Primera Instancia número 15 de Valencia, por la que se estimó totalmente el recurso contra la RDGRN, dejando sin efecto la inscripción de nacimiento y, en consecuencia, procediéndose a la cancelación del asiento de inscripción.

Sin embargo, la Sentencia dictada por la Sección Décima de la Audiencia Provincial de Valencia, de 23 de noviembre de 2011 (AC 2011\1561), desestimó también el recurso interpuesto por los apelantes, pronunciándose sobre las siguientes cuestiones: (a) Las consecuencias de la inscripción de la certificación registral extranjera; (b) La Instrucción de 5 de octubre de 2010 de la DGRN; (c) La huida de los demandantes de la aplicación de la norma imperativa española; (d) La no discriminación por razón del sexo; (e) La defensa del interés superior del menor; (f) El derecho a una identidad única.

La Sentencia de la Audiencia da preferencia, al igual que la de instancia, a la aplicación del artículo 23 LRC frente al $81 \mathrm{RRC}$, al encontrar en el texto de la Ley un impedimento para la inscripción de la filiación certificada por los funcionarios estadounidenses, que consiste en su contrariedad a la legalidad española, y en concreto al artículo 10 LTRHA, que, como se ha dicho, declara la nulidad del contrato de gestación por sustitución ${ }^{59}$.

En relación con los presupuestos que establece la Instrucción de 5 de octubre de 2010 de la DGRN, antes comentados, la Sentencia de la Audiencia determina que, aunque se dice en la demanda que la certificación californiana ha sido expedida por orden de una previa decisión judicial, lo cierto es que dicha resolución judicial no constaba en el procedimiento, ni tampoco la identidad de la madre gestante, por lo que no es posible aseverar, como hacen los apelantes (padres comitentes), que, conforme a la Instrucción de la DGRN, la filiación californiana de los menores se podría inscribir en el Registro Civil español. Igualmente, considera la Audiencia Provincial que no puede hablarse de fraude por parte del matrimonio, aunque hay indicios para pensar que han huido de la aplicación de una norma imperativa espańola, poniendo la determinación de la filiación en manos de las autorida-

59 Vid. F.J. 2. ${ }^{\circ}$ de la Sentencia de la Audiencia Provincial de Valencia, número 949/2011, de 23 de noviembre de 2011. 
des californianas mediante el desplazamiento a aquel estado y la suscripción allí de un contrato permitido según la Ley de California, que tiene por objeto además una materia, como es la filiación y el estado civil, caracterizada por la indisponibilidad ${ }^{60}$.

Señala la Audiencia Provincial, también, que no puede decirse que la Sentencia recurrida implique una infracción del principio de igualdad y de la prohibición de la discriminación por razón de sexo, de acuerdo con el artículo 14 de la Constitución, en tanto en cuanto el artículo 7.3 LTRHA permite la inscripción en el Registro Civil de la filiación a favor de dos mujeres, mientras que no se permite la inscripción a favor de dos hombres, pues las parejas de dos mujeres no necesitan acudir a otra mujer a la que encomendar la gestación. De modo que no puede considerarse discriminatorio el tratar desigualmente lo que es desigual, ya que, en el supuesto de que una pareja de mujeres acudiera a la gestación por sustitución también le sería aplicable la prohibición ${ }^{61}$.

Respecto a la vulneración del principio del superior interés del menor tanto por aplicación de la Convención sobre los Derechos del Nińo de 20 de noviembre de 1989 , que proclama este principio en su artículo 3, como por aplicación del artículo 39 de nuestra Norma Suprema o de las disposiciones de la Ley Orgánica 1/1996, de 15 de enero, de Protección Jurídica del Menor (RCL 1996\145), así como de las normas concordantes del Código Civil, la satisfacción de dicho interés no puede conseguirse infringiendo la Ley, máxime cuando la Ley española ofrece cauces para la inscripción de la filiación de los menores a favor de los demandados ${ }^{62}$.

Por último, tal y como alegó el Ministerio Fiscal en su escrito de oposición al recurso de apelación, la Sentencia recurrida no atenta contra el derecho a la identidad única de los menores, pues éstos tienen la que resulta de la certificación californiana, que será la que publique el Registro Civil español si acceden a él de acuerdo con la Ley ${ }^{63}$.

\subsection{Sentencia de la Sala de lo Civil del Tribunal Supremo, de 6 de febrero DE 2014}

Como era de esperar, el matrimonio interpuso recurso de casación contra la Sentencia de la Audiencia Provincial de Valencia. Recurso que fue desestimado por el pleno del Tribunal Supremo, confirmándose nuevamente la cancelación de la inscripción de nacimiento de los menores, a través de la Sentencia del Tribunal Supremo, número 835/2013, de 6 de febrero de 2014 (MP: Sarazá Jimena; RJ

${ }^{60} \mathrm{Vid}$. F.J. 3. ${ }^{\circ}$ de la Sentencia de la Audiencia Provincial de Valencia, número 949/2011, de 23 de noviembre de 2011.

${ }_{61}$ Vid. F.J. $4 .^{\circ}$ de la Sentencia de la Audiencia Provincial de Valencia, número 949/2011, de 23 de noviembre de 2011.

62 Vid. F.J. 5. ${ }^{\circ}$ de la Sentencia de la Audiencia Provincial de Valencia, número 949/2011, de 23 de noviembre de 2011.

63 Vid. F.J. 5. ${ }^{\circ}$ cit. de la SAP. 
20141833). Los recurrentes basaron la interposición del recurso en un único motivo, que fue la infracción del artículo 14 de la Constitución, por vulneración del principio de igualdad, en relación con el derecho a la identidad única de los menores y al interés superior de los menores consagrados en la Convención de Derechos del Niño ${ }^{64}$.

Los principales argumentos que sustentan la Sentencia pueden resumirse en los tres siguientes:

En primer lugar, entiende el Tribunal Supremo que la certificación registral aportada por los recurrentes no puede acceder a nuestro Registro Civil porque vulnera el orden público internacional español al disponer en el último párrafo del fundamento de derecho tercero de la Sentencia que la filiación cuyo acceso al Registro Civil se pretende es frontalmente contraria al artículo 10 LTRHA y, como tal, incompatible con el orden público, lo que impide el reconocimiento de la decisión registral extranjera en lo que respecta a la filiación que en ella se determina. Además, según la Sentencia, en nuestro ordenamiento jurídico y en el de la mayoría de los países con ordenamientos basados en similares principios y valores, no se acepta que la generalización de la adopción, incluso internacional, y los avances en las técnicas de reproducción humana asistida vulneren la dignidad de la mujer gestante y del niño, mercantilizando la gestación y la filiación, cosificando a la mujer gestante y al nińo, permitiendo a determinados intermediarios realizar negocio con ellos, posibilitando la explotación del estado de necesidad en que se encuentran mujeres jóvenes en situación de pobreza y creando una especie de ciudadanía censitaria en la que sólo quienes disponen de elevados recursos económicos pueden establecer relaciones paternofiliales vedadas a la mayoría de la población ${ }^{65}$.

En segundo lugar, rechaza la existencia de discriminación por razón de sexo u orientación sexual ${ }^{66}$, y reitera que la causa de denegación de la inscripción de la filiación no es que ambos solicitantes sean varones, sino que la filiación pretendida trae causa de un contrato de gestación subrogada, a lo que ańade que la solución habría de ser la misma si los contratantes formaran un matrimonio homosexual de mujeres, un matrimonio heterosexual, una pareja de hecho o una sola persona, hombre o mujer ${ }^{67}$.

Y, en tercer lugar, consideró el Tribunal Supremo que el interés superior del menor es un concepto jurídico indeterminado, esto es, una cláusula general susceptible de concreción, que el legislador introduce de forma consciente para ampliar los márgenes de la ponderación judicial, que debe ser aplicada al caso concreto ${ }^{68}$.

64 Vid. F.D. 2.1 de la Sentencia del Tribunal Supremo, número 835/2013, de 6 de febrero de 2014.

65 Vid. F.D. 3.6 de la Sentencia del Tribunal Supremo, número 835/2013, de 6 de febrero de 2014 .

${ }^{66}$ Vid. F.D. 4.1 de la Sentencia del Tribunal Supremo, número 835/2013, de 6 de febrero de 2014 . de 2014 .

${ }^{67}$ Vid. F.D. 4.2 cit. de la STS.

68 Vid. F.D. 5.3 de la Sentencia del Tribunal Supremo, número 835/2013, de 6 de febrero 
Asimismo, el Alto Tribunal instó al Ministerio Público para que ejercitase las acciones pertinentes para determinar, en la medida de lo posible, la correcta filiación de los menores, tomando en consideración, en su caso, su efectiva integración en el núcleo familiar de facto ${ }^{69}$.

Para minorar los efectos negativos que produce sobre los menores la falta de reconocimiento en España de la filiación de los mismos, acreditada por la certificación registral extranjera, el Tribunal Supremo sugiere dos soluciones compatibles entre sí: (a) Que el progenitor biológico de los menores reclame judicialmente la filiación; (b) Que los comitentes soliciten ex novo, en España, su adopción o su acogimiento familiar (STS 6 febrero 2014, F.D. 5.11) ${ }^{70}$.

Pese a la desestimación del recurso de casación (aunque la Sentencia cuenta con un voto particular ${ }^{71}$ ), los padres comitentes interpusieron un recurso extraordinario de nulidad de actuaciones por vulneración de derechos fundamentales, que concluyó con el Auto del Tribunal Supremo de 2 de febrero de 2015 (MP: Sarazá Jimena; JUR 2015\47648, en adelante, ATS) ${ }^{72}$, con idéntico sentido desestimatorio, contando también este ATS con un voto particular ${ }^{73}$, en los que no profundizare-

69 Vid. fallo de la Sentencia del Tribunal Supremo, de 6 de febrero de 2014.

70 Calvo Caravaca, A.L., «Gestación por Sustitución y Derecho Internacional Privado. Más allá del Tribunal Supremo y del Tribunal Europeo de Derechos Humanos», Cuadernos de Derecho Transnacional, (octubre 2015), vol. 7, n. ${ }^{\circ} .^{\circ}$, pp. 92-93.

${ }^{71}$ Que lo formula el magistrado D. José Antonio Seijas Quintana, y al que se adhieren los magistrados D. José Ramón Ferrándiz Gabriel, D. Francisco Javier Arroyo Fiestas y D. Sebastián Sastre Papiol. Entienden los magistrados que no debe aplicarse el artículo 10 LTRHA al tratarse del reconocimiento de una decisión extranjera en la que ya se ha determinado la filiación y que no hay vulneración del orden público. VAquero Pinto, M.J., «¿Debe admitirse y regularse la gestación por sustitución?», en Barber Cárcamo, R., Quicios Molina, S. y Verdera Server, R. (coords.), Retos actuales de la Filiación, Asociación de Profesores de Derecho Civil, Tecnos, Madrid, 2018, p. 242.

72 Este ATS fue resuelto después de que el Tribunal Europeo de Derechos Humanos (en lo sucesivo, TEDH) dictara las sentencias de los casos Labasse (asunto 65941/11) contra Francia y Mennesson (asunto 65192/11) contra Francia. En dichos procedimientos se dilucidó la vulneración del artículo 8 del Convenio para la Protección de los Derechos Humanos y de las Libertades Fundamentales, hecho en Roma el 4 de noviembre de 1950 (RCL 1979\2421, en adelante, CEDH), en relación con el derecho al respeto a la vida privada y familiar, dado que Francia había denegado la inscripción de los descendientes de ambos matrimonios en el Registro Civil por vulneración del orden público internacional francés. Ambos casos fueron resueltos mediante las Sentencias de 26 de junio de 2014 (caso Labasse JUR 2014\176905; caso Mennesson JUR 2014\176908). El TEDH apreció la violación del citado artículo $8 \mathrm{CEDH}$, por considerar que se había producido la infracción del derecho a la vida privada de los recién nacidos, en base al argumento de que el derecho a la identidad forma parte integral de la noción de vida privada. El ATS realiza la comparación de los casos franceses y el español para constatar que el TEDH no considera como violación del derecho a la vida privada cualquier decisión que afecte a la filiación. VAquero Pinto, M.J., op. cit., p. 244.

73 Por el que se apartan del criterio mayoritario los magistrados D. José Ramón Ferrándiz Gabriel, D. José Antonio Seijas Quintana Francisco, D. Javier Arroyo Fiestas y D. Sebastián Sastre Papiol, al discrepar en lo que se refiere a la trascendencia que, en el caso objeto de este incidente, han tenido las sentencias dictadas por el TEDH en los casos Labassee contra Francia y Mennesson contra Francia; y en el caso Paradiso y Campanelli (asunto 25358/12) contra Italia-Sentencia 27 de enero de 2015 (TEDH 2015\17)-. Vid. párrafo primero del voto particular del ATS. En relación con el 
mos por motivos de tiempo y espacio, quedando de este modo firme la Sentencia del Juzgado de Primera Instancia número 15 de Valencia, de 15 de septiembre de 2010, tras el largo iter judicial $^{74}$.

\section{POSTURA DE LA DGRN TRAS EL FALLO DEL TRIBUNAL SUPREMO}

La STS de 6 de febrero de 2014 mantuvo una posición contraria a lo dispuesto por la DGRN. Pese a ello, el centro directivo emitió una Circular, con fecha 11 de julio de 2014, ordenando la inscripción de las filiaciones derivadas de los contratos de gestación por sustitución conforme con la Instrucción de 5 de octubre de 2010, por considerar que dicha sentencia no afectaba a su aplicación, ya que se refería a un supuesto en el que lo que se pretendía era la simple transcripción de una certificación registral ${ }^{75}$. De tal modo que nos encontramos ante un conflicto con dos extremos opuestos. Por un lado, se encuentra la postura de la DGRN, que permite el acceso al Registro Civil de la filiación de los hijos de españoles nacidos en el extranjero mediante esta técnica de reproducción humana asistida, siempre y cuando se cumplan los requisitos establecidos en la citada instrucción; y, por otro lado, tenemos la postura de nuestro Alto Tribunal, que rechaza su acceso al Registro Civil. Sin embargo, tras la STS de 6 de febrero de 2014, se podía haber producido un cambio de paradigma, dado que se hubiera podido plantear la cuestión de si la STS no sólo anulaba la RDGRN, sino si afectaba también a los criterios de la Instrucción de 5 de octubre de 2010, y por tanto a la vigencia de esta última. Cuestión que fue resuelta tras la Circular de 11 de julio de 2014 de la DGRN, que mantuvo la vigencia de la Instrucción, frente al criterio mayoritario del TS en relación con la RDGRN, reflejado en el iter judicial tanto en la STS de 6 de febrero de 2014 como posteriormente en el ATS de 2 de febrero de $2015^{76}$.

caso Paradiso y Campanelli ver también la Sentencia de la Gran Sala, de 24 de enero de 2017 (JUR 2017\25806). Igualmente, los magistrados consideran que la solución alcanzada por la mayoría no ha realizado una adecuada ponderación de los bienes jurídicos en conflicto, que toma en consideración primordial no sólo el interés superior de los menores, sino la incertidumbre jurídica que la situación genera y seguirá generando en tanto no se dé respuesta a su solicitud de inscripción. Vid. último párrafo del voto particular del ATS.

${ }^{74}$ No obstante, los recurrentes, una vez agotada la jurisdicción ordinaria, interpusieron recurso de amparo ante el Tribunal Constitucional contra la STS de 6 de febrero de 2014 y el ATS de 2015, que fue inadmitido a trámite. González Carrasco, M.C., "Gestación por sustitución: regular o prohibir», Revista CESCO de Derecho de Consumo, núm. 22, 2017, p. 120.

75 Vaquero Pinto, M.J., op. cit., p. 240.

${ }^{76}$ Llama la atención que, pese a la negativa de la Sala Primera de lo Civil del Tribunal Supremo, y su postura encontrada con la de la DGRN, la Sala Cuarta de lo Social del Alto Tribunal haya mantenido una postura favorable a la concesión de la prestación de maternidad. En este sentido se pronuncia la Sentencia del Tribunal Supremo, de la Sala de lo Social, número 881/2016, de 25 octubre de 2016 (RJ 201616167). Este posicionamiento de la Sala de lo Social, que ha obviado lo dispuesto por el artículo 10.1 LTRHA y ha colocado el interés superior del menor por encima de 
Cabe destacar también la sorpresa que supuso la Instrucción de 14 de febrero de 2019 de la $\mathrm{DGRN}^{77}$, sobre actualización del régimen registral de la filiación de los nacidos mediante gestación por sustitución, en lo que sin duda pretendía ser un cambio evolutivo respecto a la Instrucción de 2010. Sin embargo, a los dos días se publicó por parte del Gobierno de España una nota de prensa en la que se comunicaba que se dejaba sin efecto la citada instrucción enviada a los registros consulares sobre gestación subrogada en el extranjero ${ }^{78}$. Publicándose, días después, la Instrucción de 18 de febrero 2019 de la DGRN, sobre actualización del régimen registral de la filiación de los nacidos mediante gestación por sustitución (RCL 2019\268), por la que se dejaba sin efecto la Instrucción de 14 de febrero de 2019, quedando así nuevamente vigente la Instrucción de 5 de octubre de 2010 de la DGRN.

\section{HACIA UNA LEY DE GESTACIÓN SUBROGADA}

No podemos finalizar este artículo sin hacer referencia a los intentos por legalizar esta controvertida cuestión desde el ámbito político. Así, podemos decir que ante el crecimiento del número de españoles que están recurriendo a esta técnica de reproducción humana asistida ${ }^{79}$, reservada en la actualidad únicamente a aquellas personas con una elevada solvencia económica, el Grupo Parlamentario Ciudadanos presentó, por primera vez en el Congreso de los Diputados, la Proposición de Ley reguladora del derecho a la gestación por subrogación, que se publicó en el Boletin Oficial de las Cortes Generales el 8 de septiembre de $2017(122 / 000117)^{80}$, a la cual se opusieron el resto de formaciones. Pese a ello, el partido político volvió a intentar introducir, por segunda vez, en el debate parlamentario la regulación legal de esta técnica de reproducción humana asistida, mediante la Proposición de Ley reguladora del derecho a la gestación por sustitución, publicada en el Boletín Oficial de las Cortes Generales el 16 de julio de $2019(122 / 000015)^{81}$.

cualquier otra consideración, puede interpretarse como un apoyo a la doctrina de la DGRN, frente a lo sostenido por la Sala de lo Civil del TS. Quicios Molina, op. cit., p. 25.

77 Que no fue publicada en el $B O E$, aunque se puede encontrar en el siguiente enlace: https:// www.elindependiente.com/wp-content/uploads/2019/07/instrucci\%C3\%B3n-14-febrero-2019.pdf (último acceso: 2/01/2021).

${ }^{78}$ Dicha nota de prensa está disponible en el siguiente enlace: https://www.lamoncloa.gob. es/serviciosdeprensa/notasprensa/justicia/Paginas/2019/160219gestacion-subrogada.aspx (último acceso: 3/01/2021).

79 El derecho es un instrumento dinámico que debe dar respuesta a las demandas sociales, y en España existe una demanda real en este sentido. FARnós Amorós, E., «¿Debe permitirse la gestación por sustitución en Espańa?», en CASADO, M. (coord.), De la solidaridad al mercado: el cuerpo humano y el comercio biotecnológico, Fontamara, México, 2016, p. 224.

${ }^{80}$ XII Legislatura. Serie B: Proposiciones de Ley. Disponible en http://www.congreso.es/ public_oficiales/L12/CONG/BOCG/B/BOCG-12-B-145-1.PDF\#page=1 (último acceso: 5/01/2021).

${ }^{81}$ XIII Legislatura. Serie B: Proposiciones de Ley. Disponible en http://www.congreso.es/ public_oficiales/L13/CONG/BOCG/B/BOCG-13-B-46-1.PDF (último acceso: 7/01/2021). 
En ambas ocasiones se ha generado un encendido debate, no sólo entre nuestros representantes, sino también entre la propia ciudadanía.

La estructura de la Proposición de Ley de $2019^{82}$ no difiere en demasía de su antecesora, cuyo articulado sigue distribuyéndose en 7 capítulos $^{83}$, que apenas revisten cambios respecto de la Proposición de Ley de 2017. Sí llama la atención el cambio de su nomenclatura, pues en este último caso han preferido optar por el término de sustitución frente al de subrogación, si bien es cierto que en el desarrollo de la misma continúan utilizándolo indistintamente en diferentes artículos ${ }^{84}$.

El primero de los capítulos recoge las disposiciones generales, en concreto el objeto y los principios rectores, las definiciones necesarias, los requisitos de la gestación por sustitución y la naturaleza altruista de la misma ${ }^{85}$. Es en este capítulo en donde encontramos las principales novedades respecto de la Proposición de Ley de 2017, puesto que es en la actual en la que se establece que no existirá impedimento para la existencia de vínculo de consanguineidad entre la mujer gestante y los progenitores subrogantes ${ }^{86}$.

Sorprende, sin embargo, que, pese a que se contempla ahora la posibilidad de existencia de un vínculo de consanguinidad entre los comitentes y la mujer gestante, se continúa manteniendo la compensación resarcitoria, sobre todo en lo que respecta al lucro cesante inherente al proceso de gestación, que podrá recibir la mujer gestante, la cual, desde nuestro punto de vista, puede encubrir una auténtica retribución, que fuera en contra de la naturaleza altruista de este contrato ${ }^{87}$.

El segundo capítulo regula los derechos de los cuales son titulares, y los requisitos que deben cumplir, los sujetos ${ }^{88}$ intervinientes en el procedimiento de nes finales.

${ }^{82}$ Actualmente admitida a trámite parlamentario.

${ }^{83}$ Con un total de 27 artículos, una disposición derogatoria única y cuatro disposicio-

${ }^{84}$ Véase por ejemplo en la extensa exposición de motivos o en los artículos 13 o 24.2 c) $9 .^{\circ}$. Entendemos que este indiferente uso trata de evitar la reiteración del mismo término.

85 «Aunque la ausencia de precio no puede asegurar que la gestación por sustitución no acabe convirtiéndose en un negocio de mercantilización de los cuerpos de las mujeres [...] la prohibición de precio no resuelve esta cuestión, ni puede garantizar que no existirán intereses económicos». González Carrasco, M.C., op. cit., p.119.

${ }^{86}$ En el artículo 4.3 de la Proposición de Ley de 2017 (su correlativo en la actual) se establecía que «La mujer gestante por subrogación no podrá tener vínculo de consanguineidad con el o los progenitores subrogantes». Esto hubiera supuesto una dificultad ańadida para los comitentes a la hora de encontrar a una mujer gestante en España, dada la naturaleza gratuita de este contrato.

${ }^{87}$ Ver artículo 5.1 y 5.2 de la Proposición de Ley de 2019.

${ }_{88}$ Conforme con el artículo 7.1 de la Proposición de Ley de 2019, la mujer gestante deberá cumplir los siguientes requisitos generales: a) Ser mayor de 25 (no basta con la capacidad de obrar general, sino que se requiere tener capacidad especial, al igual que ocurre con la adopción [ver artículo 175 del Código Civil]. No puede, por tanto, tener modificada judicialmente su capacidad de obrar, sino que debe tener capacidad de obrar plena en el momento de celebrar el contrato y recibir la información previa necesaria para formar válidamente su voluntad y prestar así su consentimiento. Quicios Molina, S., op. cit., pp. 40-41) y menor de la edad que reglamentariamente se fije en función de las condiciones psicofísicas que se consideren adecuadas para la gestación con éxito. b) Estar en posesión de plena capacidad de obrar (en el nuevo texto no se hace referencia a la capacidad jurí- 
gestación por sustitución, así como el contenido ${ }^{89}$ del contrato de gestación y la forma en que debe formalizarse. De este capítulo resulta de interés resaltar que la mujer gestante tiene derecho a gestar, sin aportar material genético propio ${ }^{90}$, al hijo o hijos del progenitor o progenitores subrogantes. Además, de no modificarse ni suspenderse ni derogarse los derechos que a la mujer le reconoce la legislación general, en particular, la Ley Orgánica 2/2010, de 3 de marzo, de salud sexual y reproductiva y de la interrupción voluntaria del embarazo (RCL 20101534), en cuya virtud la mujer gestante podrá interrumpir el proceso, dentro de los supuestos reconocidos por la legislación general, en pleno ejercicio de su autonomía y sin consecuencia negativa alguna para ella.

Destaca también el cambio de operador jurídico respecto al control de legalidad del contrato de gestación. Así, en la Proposición de 2019 se ha optado por realizar la propuesta del contrato de gestación por sustitución ante la autoridad judicial competente, y no ante notario, con carácter previo a cualquier aplicación de una técnica de reproducción humana asistida, redactada de forma accesible y comprensible tanto para la mujer gestante ${ }^{91}$ como para los progenitores subrogantes. Ade-

dica). c) Tener buen estado de salud psicofísica, conforme a lo dispuesto en el artículo 5.6 LTRHA, respecto de las exigencias fijadas a los donantes. d) Tener buen estado de salud mental y, en particular, no haber sufrido episodios de depresión o desórdenes psíquicos. e) Haber gestado, al menos, un hijo con anterioridad. f) Disponer de una situación socioeconómica, así como familiar, adecuadas para afrontar la gestación en condiciones óptimas de salud, bienestar y seguridad. g) Poseer la nacionalidad española o residencia legal en España. h) No tener antecedentes penales. i) No tener antecedentes de abuso de drogas o alcohol. j) No haber sido mujer gestante en más de una ocasión con anterioridad. Respecto al progenitor subrogante, el artículo 8.2 de la Proposición de Ley de 2019 establece que deberá cumplir los siguientes requisitos: a) Ser mayor de 25 años (se requiere también capacidad especial) y menor de 45 ańos. b) Estar en posesión de plena capacidad de obrar (tampoco aquí se hace referencia con la nueva redacción a la capacidad jurídica). c) Tener la nacionalidad espańola o residencia legal en España. d) Acreditar, mediante certificado de idoneidad, que cuenta con la capacidad, aptitud y motivación adecuadas para ejercer la responsabilidad parental asociada a la familia que pretende constituir. En el caso de parejas, deberán estar unidas por el vínculo matrimonial, o una relación equivalente reconocida por la Ley.

${ }^{89}$ Conforme con lo dispuesto en el artículo 9.2 de la Proposición de Ley de 2019, el contrato de gestación por sustitución contendrá, como mínimo, las siguientes determinaciones: a) Identidad de las partes intervinientes. b) Consentimiento informado, libre, expreso e irrevocable de las partes intervinientes. c) Los conceptos por los cuales la mujer podrá percibir una compensación económica, conforme a lo establecido en el artículo 5.2 de la presente Ley, y forma y modo de percepción de la misma. d) Técnicas de reproducción humana asistida que se emplearán. e) Información sobre el seguro al que hace referencia el artículo 5.5 de la presente Ley. f) Forma, modo y responsables médicos del seguimiento del proceso de gestación. g) Previsión del lugar del parto y de las circunstancias en las que el o los progenitores subrogantes se harán cargo del hijo o hijos. h) Designación de tutor, de acuerdo con lo previsto en el artículo 223 del Código Civil.

90 Esto significa que no se contempla la subrogación tradicional (traditional surrogacy) o total (en donde la mujer gestante es inseminada artificialmente aportando su propio óvulo), sino la subrogación gestacional (gestational surrogacy) o parcial.

91 Conforme con el artículo 9.7 de la Proposición de Ley de 2019, la mujer gestante deberá recibir asesoría legal que garantice la compresión de todo el proceso y sus implicaciones. Esta asesoría será independiente de la del progenitor o progenitores subrogantes. 
más, dicha propuesta de contrato tiene que ser objeto de tramitación conforme al procedimiento que a tal efecto se contemple en la LJV.

El tercer capítulo aborda el proceso de la fecundación y posterior parto, así como la relación de filiación entre el progenitor o progenitores subrogantes y el menor ${ }^{92}$, incluyendo los casos de premoriencia de uno de los dos progenitores subrogantes o el fallecimiento de los progenitores subrogantes durante la gestación.

El cuarto capítulo está reservado a la creación del Registro Nacional de Gestación por Sustitución, adscrito al Registro Nacional de Donantes, así como la inscripción en el mismo de las mujeres que libremente deseen participar en la gestación por sustitución.

El quinto capítulo regula las condiciones de funcionamiento que deben reunir los centros y servicios sanitarios para llevar a cabo la gestación por sustitución, incluyendo la obtención de la calificación y autorización necesarias y su inscripción en los registros de centros y actividades.

El sexto capítulo aborda el asesoramiento y orientación de la utilización de la gestación por sustitución, que son competencia de la Comisión Nacional de Reproducción Humana Asistida.

El séptimo capítulo se refiere al régimen sancionador, en el que se tipifican las infracciones y sanciones de aquellas conductas contrarias a la legalidad ${ }^{93}$.

Por último, y como no podría ser de otra manera, la Proposición de Ley cuenta con una disposición derogatoria única, por la que se derogan todas las disposiciones normativas que se le opongan a la Ley y, en particular, el reiterado artículo 10 LTRHA, que tanto debate ha suscitado.

92 Conforme con lo dispuesto en el artículo 11 de la Proposición de Ley de 2019, en ningún momento se establecerá vínculo de filiación entre la mujer gestante y el niño o niños que pudieran nacer; ni tampoco la inscripción en el Registro Civil reflejará datos de los que se pueda inferir el carácter de la generación. En caso de parejas, el progenitor subrogante que no hubiese aportado material genético a la gestación por sustitución podrá manifestar, conforme a la LRC 2011, que consiente en que se determine a su favor la filiación respecto del hijo o hijos del progenitor subrogante que sí lo hubiese aportado. Nótese siguiendo a Gete Alonso y Calera que a lo largo de todo el iter legislativo de modificación y reformulación de la LRC 2011, operada por la Ley 19/2015, de 13 de julio, se ha mantenido el criterio de prohibición de la maternidad subrogada, aunque lo que realmente se prohíbe no es esta maternidad, sino que se mantiene la declaración de nulidad del contrato en el que se conviene conforme con lo establecido en el artículo 10.1 LTRHA. Ver Gete Alonso y Calera, M.C., "La Inscripción de Nacimiento en la Ley 20/2011. Entre el derecho a la identidad de la personal y la reserva de la maternidad», Revista de Derecho Civil, vol. v, núm. 1 (enero-marzo), 2018, pp. $18-32$ y p. 53.

93 Como consecuencia de lo dispuesto en el artículo 4.3 de la Proposición de 2019, ya no se contempla como infracción muy grave la regulada en el artículo 24 c) 7. e la Proposición de 2017 , relativa a la realización del proceso de gestación por subrogación cuando la mujer gestante tenga vínculo de consanguineidad con el o los progenitores subrogantes. 


\section{REFLEXIONES FINALES}

A la vista de todo lo anterior, y tras haber realizado este somero estudio sobre un tema tan controvertido, no podemos sino mostrarnos totalmente a favor de una profunda revisión normativa de este "anárquico rompecabezas", tal y como refiere Álvarez GonzÁlez ${ }^{94}$, que vaya más allá de la mera prohibición o nulidad del contrato de gestación por subrogación.

Consideramos que la gestación por sustitución no es más que un método de reproducción humana, que encierra un profundo debate moral que debe ser superado. Mirar hacia otro lado de la realidad, o simplemente aumentar la penalidad por realizar este tipo de praxis, no evitará que esta técnica se siga practicando. Y menos aún cuando países de nuestro entorno cultural más inmediato la han regulado ya.

Los tiempos cambian, y con ellos los esquemas de valores de las sociedades deben ir transformándose junto con las nuevas realidades sociales y familiares, ya que el instinto reproductivo está presente en la mayoría de los seres humanos. Por ello, resulta más que razonable que cada familia quiera tener descendencia, con independencia de su orientación sexual.

La situación legislativa no está acorde con los tiempos actuales. No es lógico que, en una sociedad democrática como la nuestra, sean sólo las personas más pudientes las que tengan la posibilidad de acceder a la paternidad por esta vía, al contar con los recursos económicos suficientes para poder desplazarse a otros países en donde sí está regulada y admitida esta técnica. Además de tener que conjugar, obligatoriamente, no sólo el necesario elemento de extranjería para poder llevar a cabo estos negocios jurídicos, sino el sinfín de obstáculos a los que se tienen que enfrentar fuera de nuestras fronteras, e incluso dentro de ellas, a la hora de inscribir a sus hijos en el Registro Civil español.

Por último, esperamos que se llegue a un consenso parlamentario que permita la pronta regulación de este fenómeno que tanta polémica y sentimientos encontrados está generando. Por eso, consideramos acertada para concluir estas breves páginas la cita del escritor inglés William SHAKeSPEARE: «No existe nada bueno ni malo, es el pensamiento humano el que lo hace aparecer así».

Recibido: julio de 2020; ACEPTAdo: febrero de 2021

94 Álvarez GonZÁLeZ, S., «Nuevas y viejas reflexiones sobre la gestación por sustitución», en García Rubio, M.P. (directora), Mujer, maternidad y Derecho. V Congreso sobre la feminización del Derecho Privado. Carmona V, Tirant lo Blanch, Valencia, p. 647. 